\title{
Facial Injuries in Sports
}

\section{Sporda Yüz Bölgesi Yaralanmaları}

\author{
Sabriye Ercan, Cem Çetin \\ Sports Medicine Department, Faculty of Medicine, Süleyman Demirel University, Isparta, Turkey
}

\section{S. Ercan \\ 0000-0001-9500-698X \\ C Çetin \\ 0000-0002-8151-9554}

Geliş Tarihi/Date Received: 21.11.2018

Kabul Tarihi/Date Accepted: 10.01.2019

Yayin Tarihi/Published Online: 20.05.2019

Yazışma Adresi /

Corresponding Author:

Sabriye Ercan

Süleyman Demirel Üniversitesi Tıp Fakültesi, Spor Hekimliği Anabilim Dalı, Isparta

E-mail:

sabriyeercan@gmail.com

(C2019 Türkiye Spor Hekimleri Derneği. Tüm hakları saklıdır.

\begin{abstract}
Facial injuries are frequently observed in athletes participating in contact and limitedcontact sports branches. Most of face injuries are accompanied by dental injuries. Preventive methods and measures should be taken into consideration in order to reduce the effects of trauma on the face.

In this manuscript, eye injuries, facial trauma (facial region soft tissue injuries, facial area fractures) and dental trauma will be examined and methods to prevent traumatic injuries on facial region will be reviewed.

Keywords: sports, trauma, face

\section{öz}

Özellikle temaslı ve kısmi temaslı spor branşlarına katılan sporcularda yüz bölgesi yaralanmaları sıkça gözlenmektedir. Yüz bölgesindeki yaralanmaların birçoğuna dental yaralanmalar da eşlik etmektedir. Sporcularda, yüz bölgesinde oluşan travmanın etkilerinin azaltılabilmesi için alınacak korunma önlemleri bulunmaktadır.

Bu derlemede, göz yaralanmaları, yüz bölgesi travmaları (yüz bölgesi yumuşak doku yaralanmaları, yüz bölgesi kırıkları) ve dental travmalar incelenip travmadan korunmak için alınabilecek önlemler paylaşılacaktır.

Anahtar sözcükler: spor, travma, yüz
\end{abstract}

Available at: http://journalofsportsmedicine.org and http://dx.doi.org/10.5152/tjsm.2019.134

Cite this article as: Ercan S, Cetin C. Facial injuries in sports. Turk J Sports Med. 2019;54(3):207-14.

\section{Gíriş}

Sportif aktiviteler, yüz bölgesi ve dental bölgedeki yaralanmaların başlıca nedenlerindendir. Literatürdeki veriler incelendiğinde, yüz bölgesi yaralanmalarının \%3-29'unun sportif aktivite sırasında geliştiği görülmektedir (1). Spora bağlı yüz bölgesi yaralanmalarının çoğuna dental yaralanmalar da eşlik etmektedir (2). Yüz bölgesinin karmaşık bir anatomik yapıya sahip olması nedeniyle tanı ve tedavide güçlükler yaşanabilmektedir (1). Yüz travmalı hastalarda eş zamanlı baş-boyun ve omurga yaralanmaları da görülebilmektedir (3).

Yüz bölgesi travması olan sporcu, öncelikle travmalı hastada ileri yaşam desteği prensiplerine göre değerlendirilmelidir. Bu prensipler; hava yolunun (servikal omurlara dikkat ederek muayene edilmeli), solunumun ve 
dolaşımın (hemorajinin kontrol edilmesi ile) sağlanmasını; sakatlık yaratacak sebeplerin araştırılmasını (görme duyusu, nörolojik sistem vb.); baștan topuğa kadar diğer dokuların ve çevresinin değerlendirilmesini içermektedir (1). Bilinci yerinde olmayan sporcu, olası komplikasyonları önleyebilmek adına, servikal omur yaralanması ya da intrakranial yaralanma geçirmiş olarak değerlendirilmelidir $(3,4)$.

Yaşamı tehdit eden yüz bölgesi yaralanmaları; tüm yüz fraktürü, parçalı mandibula fraktürü, penetran boyun yaralanması, larinks veya trakeal yaralanma gibi ön boyun bölgesi yaralanmaları ile çok fazla kanamaya neden olup havayolunu engelleyen yaralanmalardır (1).

Temassız sporlara göre temaslı sporlarda yaralanma riski \%10, orofasial yaralanma riski ise \%33-56 daha fazladır (5). Dövüş sporları veya ekstrem sporlar dıșında yașamı tehdit eden yüz bölgesi yaralanmaları nadir görülmekle birlikte, havayolunu etkileyen, dolaşımı bozacak düzeyde kanamaya ve görme kaybına neden olacak yaralanmalara acil müdahalenin bilinmesi önemlidir (1).

\section{Göz Yaralanmaları}

Göz yaralanmaları, konjenital olmayan 20 yaş altı körlüklerin en sık nedenidir. Beyzbol, Amerika Birleşik Devletleri'nde 5-15 yaş arasında göz yaralanmasına en sık neden olan spor branşı iken 25-65 yaş arasında göz yaralanmalarının üçte birine raketli sporlar neden olmaktadır (1).

Göz yaralanması geçiren bir hastada ayrıntılı öykü alındıktan sonra göz muayenesine geçilmelidir. İdeal göz muayenesi; görme keskinliğinin, tam eksternal muayenenin, funduskopik muayenenin, optik sinir fonksiyonunun ve pupil değerlendirmesinin, görme alanı testinin, intraokuler basınç ölçümünün ve ekstraokuler göz hareketlerinin değerlendirilmesini içermelidir. Pratik uygulamada ekipman eksikliği muayeneyi sınırlasa da aşağıda belirtilen acil muayene yöntemleri mutlaka uygulanmalıdır (6).
- Muayeneye göz ve göz çevresi dokuların inspeksiyonu ile bașlanmalıdır. Eğer gözde bütünlük kaybından şüpheleniliyorsa palpasyona geçilmeden sporcu göz hastalıkları uzmanına sevk edilmelidir.

- Gözdeki hasarın artmaması için yaralanma sahasından göz hastalıkları uzmanına ulaşana dek koruyucu göz kapaması uygulanmalıdır.

- Gözde bütünlük kaybı şüphesi yoksa göz küresi palpe edilmelidir. Göz laserasyon, şişlik, orbital sınırlarda seviye farklılığ veya diğer yaralanmalar yönünden tam olarak değerlendirilmelidir.

- Görme keskinliği göz kartları yardımıyla değerlendirilmelidir.

- Optik sinir yaralanması açısından ışık kaynağı ile her iki gözün pupil yanıtı değerlendirilmelidir.

- Rölatif afferent pupil defekti olup olmadığ belirlenmeli, pupil boyutu değerlendirilmelidir.

- Ekstraokuler göz hareketleri değerlendirilmelidir.

- Görme alanı muayenesi sporcu ile hekim karșılıklı yüz yüze otururken görsel alanın yavaş yavaş parmakla değerlendirilmesini içermelidir (1).

Sporda kimyasal göz yaralanmasına sık rastlanmamaktadır. Ancak bu tip yaralanmalarda, hastaların prognozunu acil tedaviye başlama süresi belirleyeceği için kimyasal göz yaralanması geçiren sporcunun tedavisi acilen yapılmalıdır. Kimyasal göz yaralanmalarında, hastanın gözü hiç bekletilmeden serum fizyolojik, ringer laklat ya da bolca temiz su ile yıkanmalıdır. (1).

\section{Göz yaralanmalarından korunma}

Göz ile ilgili yaralanmalar efüzyon veya korneal abrazyon gibi minor düzeyden hifema, zigoma fraktürü, orbital blow-out fraktürü veya glob rüptürü gibi major düzeye kadar uzanmaktadır (7). 
Boks haricindeki tüm spor branşlarında göz yaralanmalarının \%90'ı engellenebilir özelliktedir (6). Düşme, çarpma ve yüksek hızda hareket eden cisme karşı dirençli olan polikarbon yapıdaki gözlüklerin kullanımı göz yaralanmalarından koruyucu rol oynamaktadır (6). Koruyucu gözlüğün kırılmaya olan direnci, kalınlığı ile doğru orantılı olup $3 \mathrm{~mm}$ ve üstündeki kalınlık sportif faaliyetlerde kullanıma uygundur (7). Kask kullanımı gereken spor branşlarında, koruyucu gözlükler kaskın içine ya da üzerine takllarak kullanılabilmektedir (6).

\section{Yüz Bölgesi Travmaları}

Yüz bölgesindeki travmaların epidemiyolojisi yaşanılan bölgeye, kültüre, yaşam tarzı farklılıklarına ve sosyoekonomik duruma göre değişim göstermektedir (8-10). Laserasyon, kontüzyon, hematom, ekskoryasyon gibi yumuşak doku yaralanmaları tüm yüz bölgesi yaralanmaların \%68.3'ünde görülür (3). Yüz bölgesi fraktürleri en sık trafik kazası, saldırı, düşme ve spor yaralanması ile ilişkilidir $(9,10)$. Dünya genelinde fiziksel aktivite ve yarışmalı sporlara katılımın artması ile birlikte spora bağlı travmalar da artmaktadır (11). Yüz bölgesi, vücudun en korunmasız alanı olduğundan özellikle temaslı sporlarda bu bölgenin travma sıklığı daha fazladır (11).

Avrupa'da spor ile ilişkili yüz bölgesi travmalarinda futbol $(\% 36,6)$ maksillofasial yaralanmalara en sık neden olan branştır. Bunu Amerikan futbolu $(\% 16,1)$, kayak $(\% 9,6)$, basketbol $(\% 4,9)$, hokey $(\% 3,9)$ ve dövüş sporları $(\% 2,3)$ izlemektedir (10). Her ülkede gözde spor branșları farklı olduğu için bu oranlar ülkeden ülkeye değişiklik gösterebilmektedir $(4,12,13)$.

\section{Yüz Bölgesi Yumuşak Doku Yaralanmaları}

Yüz bölgesindeki yumuşak doku yaralanmaları, travmanın dokuda oluşturduğu hasarın derinliğine göre farklı isimler almaktadır. Abrazyon, genellikle epidermisteki sinırlı yüzeysel deri aşınmasıdır. Hafif düzeyde kanama ve terminal sinir uçları açıkta olduğu için ağrı yapabilmektedir. Abrazyon bölgesi salin ile temizlenmeli ve yabancı cisimler uzaklaştırılmalıdır. Tedavide, topikal antibiyotik ve anestezik tedavisi verilebilmektedir (14).

Kontüzyon, künt travma sonucu sıklıkla fraktür olmadan yumuşak dokuda hematom oluşmasıdır. Ancak genelde gözden kaçabilen kemik ve dentoalveolar yaralanmalar mutlaka araştırılmalıdır. Kontüzyon kendiliğinden sınırlanmaktadır. Fakat sistemik semptomların gelişmesi halinde ciddi bir yaralanma veya enfeksiyona ait bulgular araştırılmalıdır. Buz ve baskı uygulaması efüzyon gelişimini engelleyeceği için tedavide önerilmelidir (14).

Laserasyon, derinin yırtılmasıdır. Travma sonrası, bölge salin ile temizlenmeli ve yabancı cisimler bölgeden uzaklaştırılmalıdır. Kanama kontrolü için baskı uygulanmalıdır. Yara yeri; doku yapıştırıcıları ile birleştirilmeli ya da skalp bölgesi laserasyonları 5/0, yüz bölgesi laserasyonları $7 / 0$ monofilaman ile sütüre edilmelidir. Hastaya tetanoz profilaksisi verilmeli, laserasyon insan ısırığı sebebiyle oluştuysa tedaviye antibiyotik eklenmelidir (14).

Avülsiyon, zorlanma sonrası dokunun normal yerinden kopmasıdır. Eğer yumuşak dokuda avülsiyon varsa buna genellikle yaygın abrazyonlar da eşlik etmektedir. $\mathrm{Bu}$ tip yaralanma çoğunlukla deride, gözlerde, dudakta ve dişlerde oluşmaktadır. Sporcuda, ağrı ve kanama mevcuttur. Böyle bir durumda, salin ile dokuyu temizlemek ve hafif yaralanmada dokuyu sütüre etmek, ağır yaralanmalarda ise hastayı sağlık kuruluşuna yönlendirmek gerekir (14).

\section{Yüz Bölgesi Fraktürleri}

Tüm spor yaralanmalarının \%4-18'inde yüz bölgesi fraktürü gelişmektedir. Özellikle orta yüz bölgesi ve mandibula fraktürleri havayolunu etkileyeceği veya yoğun kanamaya sebep olacağl; orbita ve zigoma fraktürleri ise görme kaybına yol açacă̆ı için önem taşımaktadır (1).

Yüz iskeleti 3 bölgeye ayrlarak değerlendirildiğinde (15);

- Üst $1 / 3$ yüz bölgesinde; frontal sinüs fraktürü, orbital çatı fraktürü, 
- Orta yüz bölgesinde; nazal kemik fraktürü, septal hematom, zigoma fraktürü, maksilla fraktürü, lateral orbital duvar, medial orbital duvar, orbital taban, nazoorbitoetmoid, palatal kemik, pterigofasial (Lefort 1), zigomatikomaksiller kompleks, pterigofasial (Lefort 2 ve 3) fraktürü,

- Alt 1/3 yüz bölgesinde; mandibula fraktürü, dental travma, temporomandibular eklem dislokasyonu, kafa tabanı fraktürü görülmektedir.

Farklı olgu serilerinde en sık kırılan kemik bölgeleri ve en sık kırık gözlenen spor branşları farklılık gösterebilmektedir $(4,12)$. Literatürün derlendiği bir çalışmada mandibula fraktürünün futbol, beyzbol, Amerikan futbolu; zigoma fraktürünün kayak; nazal kemik fraktürünün basketbol; orta yüz bölgesi kırıklarının ise en çok kayak sporunda görüldüğü bildirilmiştir (7).

Futbol, Amerikan futbolu, çim ve buz hokeyi, kayak orofasial yaralanmalar için yüksek risklidir. Bunun yanında basketbol, bisiklet, ata binme, jimnastik, duvar tenisi orta düzeyde risk taşımaktadır. Yüz yaralanmaları, en sık 21-30 yaş aralığındaki bireylerde görülmektedir (4). Erkeklerde spora bağlı yüz bölgesi fraktürüne daha yüksek oranda rastlanmaktadır $(16,17)$. Erkeklerin riskli sporlara daha sık katılmaları ve/veya kadınların yüz koruyucu malzemeleri daha fazla kullanmaları bunun nedeni olabilir $(7,18)$.

Yüz bölgesi travması olan hastanın ileri yaşam desteğine ihtiyaç duymadığı saptandıysa diğer sistemlerin muayenesine geçilmelidir (19). Üst 1/3 yüz bölgesine travma almış sporcuda; fasial sinirin frontal dalı ve trigeminal sinirin oftalmik dalı kontrol edilmeli, supraorbital çatı palpe edilmelidir (19). Orta 1/3 yüz bölgesine travma almış sporcuda; gözler (görme kaybı, ekstraokuler kas fonksiyonu, glob bütünlüğü), burun (fraktür, septal hematom), zigoma, maksilla, fasial sinirin bukkal ve zigomatik dalı, trigeminal sinirin maksillar dalı kontrol edilmeli, palpasyonda ağrılı ve seviye veren bölge varlığı incelenmelidir (19). Alt 1/3 yüz bölgesine travma almış sporcuda; dudaklar, dil, yanaklar, tüm dişler, mandibula, fasial sinirin mandibular ve servikal dalı, trigeminal sinirin mandibular dalı kontrol edilmelidir. Kulak çevresinde hematom, duyma kaybı, timpanik membran veya auditor kanaldan kansız şeffaf sıvı (BOS) gelmesi kafa tabanı fraktürünün göstergesidir. $\mathrm{Bu}$ durum, acil müdahale gerektirmektedir (19).

Epistaksis, \%90 oranında anteriorinferior septum bölgesinden kaynaklanır ve genellikle başın öne eğilip buruna 15 dakika sıkı baskı uygulaması ile kontrol altına alınabilmektedir. Eğer epistaksis ile birlikte nazal ağrı ve deformite varsa sporcu nazal fraktür açısından incelenmelidir (20).

Septal hematom, persistan epistaksis ve rinore, enoftalmus, diplopi, görme kaybı, baş-boyun ağrısı ve nörolojik semptomlar varsa yaşamı tehdit eden veya orta $1 / 3$ yüz bölgesine ait komplike bir fraktür varlığının araştırılması ve acil müdahale edilmesi gereklidir (20).

Orta yüz fraktürlerinden olan orbital blow-out fraktüründe; göz hareketlerinde kısitlılık, görme kaybı, diplopi, enoftalmus, infraorbital hipoestezi, alında parestezi, pupillerde dilatasyon bulguları mevcuttur (1). Nazoorbitoetmoid fraktürde lakrimal kanal etkilenebilmektedir (17).

Zigoma fraktüründe; subkonjoktival hemoraji, periorbital ekimoz, infraorbital hipoestezi, diplopi, göz küresinde malpozisyon, palpasyonla seviye veren kemik vardır (1).

Maksilla fraktürleri, fraktür hattına göre Lefort 1-2-3 olarak sınıflandırılmaktadır (8). Lefort fraktürleri yüksek enerjili fraktürlerdir ve hava yolu obstrüksiyonuna sebep olabilmektedir. Lefort 1 fraktürü, sadece maksillada transvers fraktür hattını; Lefort 2 fraktürü maksilla ve burun çevresinde zigoma fraktürünü; Lefort 3 fraktürü ise orta yüz bölgesine ait kemiklerin kraniumdan ayrılmasını ifade etmektedir (1).

Mandibula fraktürüne, yüz bölgesindeki travmalarda sık karşılaşılır. Mandibulanın en sık kırılan bölgeleri; mandibula açısı, simfizis, subkondiler bölge ve mandibula gövdesidir (4). Sublingual hematom, mandibula fraktürünün belirtisi olabilmektedir. Mandibula fraktürü 
sırasında bukkal kanalın da etkilenmiş olabileceği unutulmamalıdır (17).

Çenenin kapanması sırasında asimetri veya tam kapanmama mandibula fraktürünün, temporomandibular eklem dislokasyonunun veya fraktürünün göstergesidir. Travma sonrası temporomandibular eklemde siklıkla hemartroz, intraartiküler disk hasarı, periartiküler yumuşak doku yaralanması ve ankiloz gelişmektedir. Hasarın tespiti için radyografi, manyetik rezonans görüntüleme ve bilgisayarlı tomografi kullanılabilmektedir. $\mathrm{Bu}$ bölgedeki ankilozun tedavisi standart değildir. Tedavide eksizyon, kondilektomi, kostokondral greft veya osteotomi tercih edilebilmektedir (17).

Yüz bölgesi fraktürü gelişmiş sporcunun antrenmana ya da yarışmaya devam etmesi uygun değildir. Sporcu, kesin tanısının konulacağı ve tedavisinin yürütüleceği sağlı kuruluşuna götürülmelidir. Mandibula fraktürü kesin tanisinda ortopantomogram ve posteroanterior grafi; zigoma fraktüründe $0^{\circ}$ ve $30^{\circ}$ 'de oksipitomental grafi; orbital ve kompleks fraktürde bilgisayarlı tomografi gereklidir. Nazal fraktüre eşlik eden herhangi bir yaralanma yoksa ek görüntüleme yöntemine ihtiyaç yoktur (21). Yer değiştirmeyen fraktür mevcutsa hastaya istirahat vermek ve konservatif (Resim 1) olarak takip etmek uygundur (4).

Yer değiştiren ya da kompleks fraktür mevcutsa cerrahi olarak internal fiksasyon uygulanmalıdır (4). Cerrahi sırasında steroid kullanımı cerrahi sonrası oluşan mide bulantısı, kusma ve efüzyon semptomlarını azaltmaktadır. Cerrahi sonrası ilk 24 saatte kullanılan antibiyotik yeterlidir (17).

\section{Yüz Bölgesi Fraktürü Sonrası Spora Geri Dönüş}

Literatürde, yüz bölgesi travmaları sonrası spora geri dönüş zamanını belirten kanıta dayalı çalışmalar mevcut değildir (1). Ancak, kemik dokunun iyileşme süreçlerine göre spora geri dönüş kararı verilebilmektedir. Kemik fraktürü sonrası, iyileşme sürecinin ilk 5 gününde inflamatuvar hematom oluşmaktadır. Bu süreci takiben 4-40 gün arasında kallus formasyonu gelişmekte ve 25-50 gün arasında yeniden düzenlenme fazına geçilmektedir. Bu süreler dikkate alınırsa, fraktürden sonraki ilk 20 gün aktivite yapılmaması önerilmektedir (1).

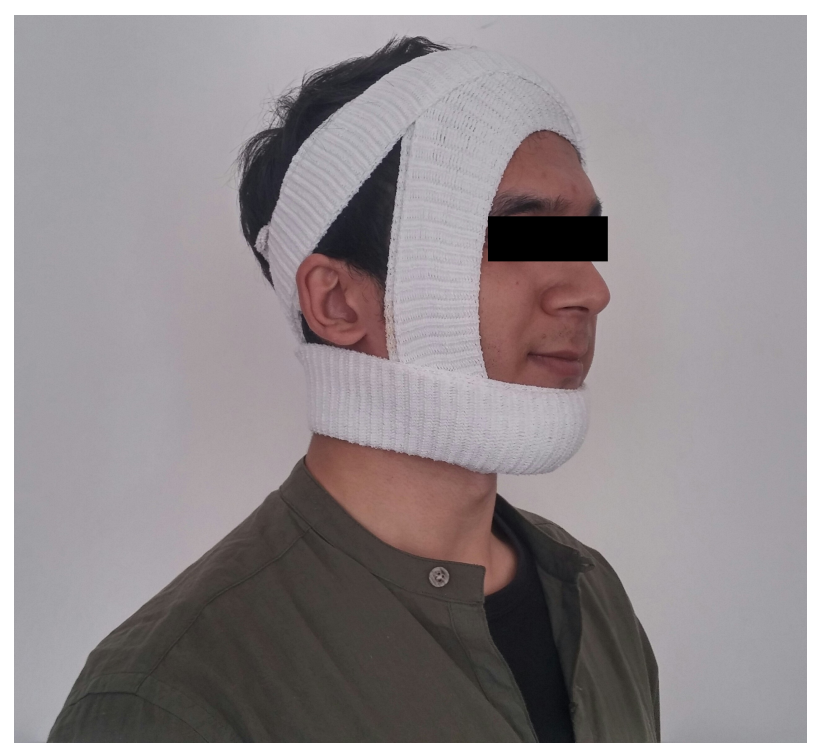

Resim 1. Barton bandajı-elastik bandaj ile maksillomandibular fiksasyon

21-30 gün arasında hafif aerobik egzersize, 3140 gün arasında temassız antrenmanlara, 41. günden sonra temaslı antrenmanlara ve spora geri dönüşe izin verilebilmektedir (1). Sporcunun bir ileri evreye geçiş kararı, ağrısız ve asemptomatik olmasına göre verilmelidir. Eğer sporcu dövüş sporları yapıyorsa 3 aydan önce spora geri dönüş izni verilmemelidir (1). Ancak yüz bölgesinde fraktür olan sporcu, koruyucu yüz maskesi gibi ekipmanları kullanarak yukarıda belirtilen sürelerden daha önce spora dönebilmektedir (1).

\section{Yüz Bölgesi Fraktürlerinden Korunma}

Yapılan çalışmalarda, 27 metre/saniye hızdan daha yüksek hızla çarpan hareketli cismin baş yaralanması riski oluşturduğu ve elit düzeyde sporcunun attığ 1 kriket topunun 30-45 metre/saniye hıza ulaştığı bildirilmiştir (7). Bu nedenle sportif aktivitelerde, kask ve yüz koruyucu malzemeleri kullanmak enerjinin emilimini sağlayarak orofasial ve baş yaralanmaları riskini $\% 85$ oranında azaltmaktadır (7). 
Çene korumalı kafes tipi, yastık destekli polikarbonat $\mathrm{H}$ tipi, yastık desteksiz polikarbonat $\mathrm{H}$ tipi ve tüm yüz koruyucu tip gibi farklı yüz koruyucu modelleri vardır (22). Koruyucular, polikarbon ya da yüksek kaliteli plastik kompozit maddelerden kişiye özel ya da standart olarak üretilebilmektedir (7). Yüz ve baş koruyucularıyla birlikte ağız koruyucularını kullanmak çene, dental ve alveolar bölgeyi de koruyacaktır (4).

\section{Dental Travma}

Temaslı sporların dental yaralanmalar için büyük risk oluşturduğu iyi bilinmektedir (23). Yüz bölgesinde fraktür gelișen sporcuların \%50'sinde dental yaralanma da görülmektedir (2). Dental yaralanmaların en sık görüldügü spor branşları; futbol, basketbol, hokey ve boks olarak rapor edilmiştir (24).

Komplike olmayan kron fraktürü (\%56), luksasyon (\%4.9), komplike kron fraktürü (\%2.4) ve dental avülsiyon (\%1.2) en slk görülen dental yaralanmalardır $(5,23,25)$. Maksilladaki ve mandibuladaki ön kesici dişler travmadan sıklıkla etkilenmektedir (26).

Dünya Sağlık Örgütü'nün sinıflamasına göre dental travmalar; kron fraktürü (mine fraktürü, komplike olmayan kron fraktürü, komplike kron fraktürü), kök fraktürleri, luksasyon (intrüzyon, ekstrüzyon, subluksasyon, avülsiyon, lateral luksasyon, konklüzyon) ve alveolar fraktürlerdir $(27,28)$.

Mine fraktürü, diș yapısında kayıp olmadan minede oluşan fraktürdür. Tedavide, minenin yapısal bütünlügünün ve canlılığının devamı sağlanmaktadır $(14,27)$.

Komplike olmayan kron fraktürü, pulpaya ulaşmamış; komplike kron fraktürü ise pulpaya ulașmıștır. Tedavide pulpanın canlılığının devamı ve dişin restorasyonu gereklidir (27).

Kök fraktürü; pulpanın açık olduğu/olmadığı, mine, dentin ve sement fraktürüdür. $\mathrm{Bu}$ durum acil tedavi gerektirir. Acil tedavinin amacı koronal parçaları stabilize etmektir. Acil tedavi sonrasında ise dişin restorasyonu sağlanmalıdır $(14,27)$.
Luksasyon, dişe destek olan dokularda gevşeme ve dişte yer değiștirme olarak tanımlanmaktadır. Subluksasyon geliştiğinde sporcu, 2 hafta boyunca splint kullandırlarak takip edilmektedir. Luksasyon durumunda ise 24 hafta esnek splintleme yapılmalı, gerekiyorsa ardından endodontik tedavi uygulanmalıdır $(14,27)$.

Avülsiyon, dişin soketinden ayrılmasıdır $(14,27)$. Sporcuda dental avülsiyon tespit edildiğinde, uygun önlemler alınarak sporcuyu hızlıca diş hekimine sevk etmek diș sağlığının prognozu açısından önemlidir (27). Travma sonrası avülse parça bulunmalı, diş kron kısmından tutulmalı, su ya da salin ile avülse diş üzerindeki yabancl maddeler uzaklaştırılmalıdır. Diş parçası, diş hekimine transferi sırasında salin, sıcak olmayan süt, diş soketi ya da kişinin dilinin altında kendi tükürügü içinde tutulmalıdır $(29,30)$. Hastada kontraendikasyon bulunmadığı sürece dişin reimplantasyonu sağlanmalıdır. İşlemden sonra 1 hafta esnek splint kullanılmalıdır. Hastaya tetanoz profilaksisi yapılmalı ve 4-7 gün süreyle antibiyotik tedavisi verilmelidir (27).

\section{Dental Travmalardan Korunma}

Yaralanmaların hem antrenman döneminde hem de yarışma sırasında geliştiği bilinmektedir (23). Bu nedenle özellikle temaslı ve kısmi temaslı spor branşlarına katılan sporcuların koruyucu malzemelerini her zaman kullanması önemlidir. Ağız koruyucular; dental ve ağız içi yumuşak doku yaralanmalarına, temporomandibular eklem hasarlarina hatta intrakranial yaralanmalara karşı koruyucu özelliktedir (27, 30-33).

Ağız koruyucular; standart, ısıt-ısır ve kișiye özel yapılan olmak üzere üç farklı tiptedir (5, 31). Özellikle diş hekimi tarafından kişiye özel yapılan ağız koruyucuların kullanımı konforludur (Resim 2). 


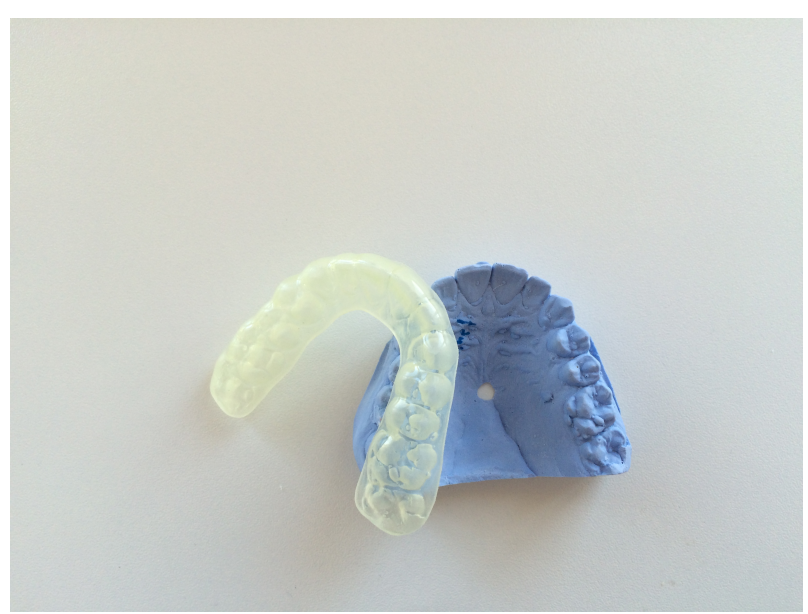

Resim 2. Kişiye özel yapılan ağız koruyucu (Fotoğrafın kullanımı için Dr. Dt. Ayşegül CEVIZOĞLU SARITEKİN'den izin alınmıştır)

Kişiye özel yapılan ağız koruyucu için en uygun kalınlığın $3 \mathrm{~mm}$ olduğu bildirilmektedir. Yapılan birçok çalışmada bu tip koruyucuların konuşmayı, nefes almayı, aerobik ve anaerobik sportif performansı etkilemediği bulunmuş ve sporcuların ağız koruyucu kullanımı için teşvik edilmesi önerilmiştir $(5,31,32,34,35)$.

\section{SONUC}

Sporcularda görülen yüz bölgesi yaralanmalarının birçoğu koruyucu önlemler ile azaltılabilmektedir. Sporcular koruyucu önlemler konusunda bilinçlendirilmeli ve koruyucu yöntemlerin kullanılması sağlanmalıdır. Tüm önlemler alınmasına rağmen gelişen yüz bölgesi travmalarında ise hekimlerin bilgisinin ve sporcuya özgü tedavi yaklaşımlarının prognoz için belirleyici olacağı akılda tutulmalıdır.

\section{KAYNAKLAR}

1. Reehal P. Facial injury in sport. Curr Sports Med. 2010;9(1):27-34.

2. Gassner R, Bösch R, Tuli T, et al. Prevalence of dental trauma in 6000 patients with facial injuries. Oral Surg Oral Med Oral Pathol Oral Radiol Endod. 1999;87:2733.

3. Hackl W, Hausberger K, Sailer R, et al. Prevalence of cervical spine injuries in patients with facial trauma. Oral Surg Oral Med Oral Pathol Oral Radiol Endod. 2001;92:370-6.

4. Mourouzis C, Koumoura F. Sports-related maxillofacial fractures: A retrospective study of 125 patients. Int J Oral Maxillofac Surg. 2005;34:635-8.
5. Soares PV, Tolentino AB, Machado AC, et al. Sports dentistry: a perspective for the future. Rev Bras Educ Fís Esporte. 2014 Jun;28(2):351-8.

6. Erdener U, Mocan MC. Sporcularda göz hastalıkları ve acil müdahale. In: Baydar ML, Çetin C, editörler.

Multidisipliner yaklaşımla sporcu sağlığı. Ankara: Fersa matbaacilı; 2011. p.9-21.

7. Farrington T, Onambele-Pearson G, Taylor RL, et al. A review of facial protective equipment use in sport and the impact on injury incidence. Br J Oral Maxillofac Surg. 2012;50:233-8.

8. Lee JH, Cho BK, Park WJ. A 4-year retrospective study of facial fractures on Jeju, Korea. J Craniomaxillofac Surg. 2010;38:192-6.

9. Bergha BVD, Karagozoglu KH, Heymans MW, et al. Aetiology and incidence of maxillofacial trauma in Amsterdam: A retrospective analysis of 579 patients. $J$ Craniomaxillofac Surg. 2012;40:165-9.

10. Boffano P, Roccia F, Zavattero E, et al. European Maxillofacial Trauma (EURMAT) project: A multicentre and prospective study. J Craniomaxillofac Surg. 2015;43:62-70.

11. Azodo CC, Odai CD, Osazuwa-Peters N, et al. A survey of orofacial injuries among basketball players. Int Dent J. 2011;61:43-6.

12. Maladiere E, Bado F, Meninguad JP, et al. Aetiology and incidence of facial fractures sustained during sports: a prospective study of 140 patients. Int J Oral Maxillofac Surg. 2001;30:291-5.

13. Gassner R, Tuli T, Hachl O, et al. Cranio-maxillofacial trauma: a 10 year review of 9543 cases with 21067 injuries. J Craniomaxillofac Surg. 2003;31:51-61.

14. Patel PB, Stanton DC, Granquist EJ. Common dental and orofacial trauma evaluation and management. Med Clin N Am. 2014;98:1261-79.

15. Tuncel N, Tercan M. A Retrospective analysis of facial fracture etiologies and investigation of the relationship between fracture type and the etiology. Dicle Med J. 2011;38(2):208-14.

16. Walker TWM, Byrne S, Donnellan J, et al. West of Ireland facial injury study. Part 1. Br J Oral Maxillofac Surg. 2012;50:631-5.

17. O'Connor RC, Shakib K, Brennan PA. Recent advances in the management of oral and maxillofacial trauma. Br J Oral Maxillofac Surg. 2015;53:913-21.

18. Walker TWM, Donnellan J, Byrne S, et al. West of Ireland facial injury study. Part 2. Br J Oral Maxillofac Surg. 2012;50:99-103.

19. Luke AC. Baş ve boyun yaralanmaları. Çeviri: Yıldız Y. In: Gür H, Türkçe basım editörü. FIMS takım doktoru el kitabı.2. basım. İstanbul: ER-AY Basım Hizmetleri Tic.Ltd.Şti;2009.p.440-74.

20. Razavi A, Farboud A, Skinner R, et al. Acute nasal injury. BMJ 2014; 349. doi: http://dx.doi.org/10.1136/bmj.g6537.

21. Hammond D, Wain R, Reed A, et al. A guide to sportbased injuries for the hospital-based dental trainee. FDJ. 2016;7(1):34-9.

22. Gandy JR, Fossett L, Wong BJF. Face Masks and Basketball: NCAA Division I Consumer Trends and A 
Review of Over-the-Counter Face Masks. Laryngoscope. 2016; 126 (5): 1054-60.

23. Emerich K, Nadolska-Gazda E. Dental trauma, prevention and knowledge concerning dental first-aid among Polish amateur boxers. JSAMS. 2013;16:297301.

24. Tulunoglu I, Ozbek M. Oral trauma, mouthguard awareness, and use in two contact sports in Turkey. Dent Traumatol. 2006;22:242-6.

25. Faus-Damiá M, Alegre-Domingo T, Faus-Matoses I, et al. Traumatic dental injuries among school children in Valencia, Spain. Med Oral Patol Oral Cir Bucal. 2011;16(2):292-5.

26. Thoren H, Numminen L, Snall J, et al. Occurrence and types of dental injuries among patients with maxillofacial fractures. Int J Oral Maxillofac Surg. 2010;39:774-8.

27. Deniz Y, Zengin AZ, Con M. Sports related dental trauma, treatment and prevention methods. OMÜ SPD. 2015;6(2):79-89.

28. Bastone EB, Frer TJ, McNamara JR. Epidemiology of dental trauma: A review of the literature. Aust Dent J. 2000;45:(1):2-9.
29. Emerich K, Kaczmarek J. First Aid for Dental Trauma Caused by Sports Activities State of Knowledge, Treatment and Prevention. Sports Med. 2010;40(5):361-6.

30. Sigurdsson A. Evidence-based Review of Prevention of Dental Injuries. J Endod. 2013;39:88-93.

31. Tuna EB, Ozel E. Factors Affecting Sports-Related Orofacial Injuries and the Importance of Mouthguards. Sports Med. 2014;44:777-83.

32. Kececi AD, Eroglu E, Baydar ML. Dental trauma incidence and mouthguard use in elite athletes in Turkey. Dent Traumatol. 2005;21:76-9.

33. Mihalik JP, McCaffrey MA, Rivera EM, et al. Effectiveness of mouthguards in reducing neurocognitive deficits following sports-related cerebral concussion. Dent Traumatol. 2007;23:14-20.

34. Cetin C, Kececi AD, Erdogan A, et al. Influence of custom-made mouth guards on strength, speed and anaerobic performance of taekwondo athletes. Dent Traumatol. 2009;25(3):272-6.

35. Kececi AD, Cetin C, Eroglu E, et al. Do custom-made mouth guards have negative effects on aerobic performance capacity of athletes?. Dent Traumatol. 2005;21(5):276-80. 